\title{
Zero-a-seis
}

\section{A constituição da infância permeada pelo contexto social, mídia e brinquedo}

Este artigo tem como objetivo desenvolver tópicos ligados à Cultura da criança. Os assuntos abordados versam desde as teorias relacionadas à história das infâncias e do brinquedo, bem como seu papel nas culturas infantis, além de entrevistas realizadas com as crianças até a prática que envolve as brincadeiras das diferentes infâncias. $\bigcirc$ presente artigo traz argumentos sobre processos que envolvem a interação da mesma com seu brinquedo e, também as razões que levaram a sua escolha, buscando enfatizar as vantagens e desvantagens, bem como citar suas utilizações e tipos disponíveis no mercado. Ao fazer a análise deste mercado, serão relatadas as estratégias utilizadas pelo marketing e publicidade para atrair o grande público consumista infantil. Esta pesquisa toma como base, a teoria e a prática elaboradas por autores do meio acadêmico como, bem como as contribuições estabelecidas no seio das famílias que são as primeiras a participar no processo educativo.

Palavras- chave: infâncias, crianças, brinquedos, mídia.

\section{Childhood constitution permeated by social, media and toy}

This paper aims to develop topics related to the child's culture. The subjects covered Versam from theories related to the history of childhood and toys, as well as its role in children's culture, plus interviews with the children to practice that involves the games of different childhoods. This article presents arguments about processes that involve the interaction of it with her toy and also the reasons for their choice, seeking to emphasize the advantages and disadvantages as well as citing their uses and types available in the market. By doing this market analysis, will be reported strategies used by marketing and advertising to attract a large audience consumerist child. This research builds on the theory and practice developed by authors from academia as well as the contributions established within families who are the first to participate in the educational process.

Keywords: childhood, children, toys, media.

I Doutorando em Educação em Ciências pela Universidade Federal do Rio Grande do Sul (UFRGS), bolsista Capes. Professor da Universidade Federal de Pelotas (UFPel) e-mail: kelberabrao@gmail.com

2 Graduada em Pedagogia pela Universidade Federal de Rio Grande (FURG).Professora da rede municipal de ensino de Rio Grande. E-mail: dr.abrantes@yahoo.com.br

3 Graduada em Pedagogia pela Universidade Federal de Rio Grande (FURG). Professora da rede municipal de ensino de Rio Grande. E-mail: daiadorf@hotmail.com

4 Doutorando em Educação pela Universidade Federal de Pelotas (UFPel).E-mail: mcslouzada@gmail.com 
s relatos que seguem neste artigo abordam as trajetórias da infância, objeto brinquedo que busca evidenciar questões ligadas ao brinquedo como objeto simbólico e cultural, presente nas diferentes infâncias, o papel do brinquedo na cultura da criança, a qual faz uma abordagem reflexiva sobre a influência da mídia nas crianças, bem como, traz, através de entrevistas, depoimentos das mesmas, também as contribuições sobre a construção da identidade através das brincadeiras, que discorre brevemente sobre a importância da imitação dos adultos, pelas crianças, para a construção de sua identidade e, por fim são tecidas algumas considerações.

\section{Trajetórias da Infância}

Alguns estudiosos, como Brougère (1995), Souza (2000), Postman (1999) e Abrão (2011), Dorneles (2005), buscam explicar a história das infâncias em nossas civilizações, a qual é marcada por inúmeras contradições. Atualmente, também existem algumas teorias que procuram problematizar os caminhos pelo qual as infâncias vêm tomando, levando-se em consideração os diferentes processos de transformação econômica, científica, cultural e tecnológica da sociedade.

Para melhor entender a constituição infantil dos sujeitos de hoje, é necessário saber quem é, ou quem são as crianças da atualidade. Pode-se compará-las com as crianças do passado ou da modernidade?

Postman (1999), através da obra "O desaparecimento da Infância” faz uma análise bastante crítica e pessimista sobre a situação da infância contemporânea, "ele atribui à televisão a grande responsabilidade pela ideia do desaparecimento da infância", devido à acessibilidade às informações que as crianças começaram a adquirir através da TV e por outros meios de comunicação (telefone, rádio, máquina de fotografia, entre outros), visto que, na década de 50, iniciou-se uma revolução na forma como a informação passou a ser divulgada. A televisão começou a mostrar todos os segredos do mundo adulto, os quais eram escondidos na Idade Média e Moderna; cenas de violência, sexo, mentira, traição, corrupção, e pedofilia, tornaram-se questões do cotidiano das crianças e adolescentes. 
A criança passa a aprender o que acontece no mundo, sem ter, muitas vezes, a mediação de um adulto, visto que, este tem a necessidade de ausentar-se por um longo período em função do trabalho que lhe ocupa muito tempo, devido às exigências do mercado capitalista. As famílias, em geral, já não conversam mais, algumas pouco se interessam sobre os assuntos do cotidiano das crianças, conforme Souza (2000, p. 94):

\begin{abstract}
Nos lares de hoje as famílias não mais contam suas histórias. $\bigcirc$ convívio familiar se traduz na interação muda entre pessoas que se esbarram entre os intervalos dos programas da TV e o navegar através do éden eletrônico das infovias $\bigcirc$ tato e o contato entre as pessoas, na casa ou no trabalho, cedem lugar ao impacto televisual.
\end{abstract}

Para evidenciar esta questão, destaca-se a obra de Dornelles (2005) "Infâncias que nos escapam: da criança de rua à criança cyber", na qual a autora procura fazer uma compreensão entre as diferentes culturas infantis, desde as crianças em situação de baixa renda, abandonadas, sem acesso às tecnologias, até aquelas consideradas crianças cybers, que são altamente globalizadas, informatizadas, com conhecimentos que vão além de suas idades, assustando pais e educadores, os quais, na maioria das vezes, não conseguem controlá-las.

As crianças de hoje, devido a este acesso facilitado a tecnologia e a mídia, tornaram-se verdadeiras consumidoras, elas são produtos da sociedade capitalista e seletiva, pois beneficia uns em detrimento de outros, como consequência desses problemas percebe-se que não existe uma infância homogênea, por este motivo torna-se complicado definir quem são as crianças de hoje. Segundo Dornelles (2005, p. 94), "não se consome apenas o objeto em si, mas tudo aquilo que ele possa representar para meninos e meninas, status, conforto, desejos e beleza, saber e poder", por mais que exista diferença de classes sociais entre as infâncias, os desejos de consumo dos produtos em evidência na mídia, são os mesmos, porém, sabe-se que estes estarão disponíveis apenas para crianças pertencentes a um determinado grupo social, as menos favorecidas acabam, de certa forma, sendo excluídas dessa realidade.

\title{
O objeto brinquedo
}

Ao remetermos ao brinquedo muitas outras questões além da infância estão relacionadas. A influência que tal, exerce na vida de uma criança, sua grande importância independente do nível social, a intensificação muitas vezes de forma apelativa e insistente da mídia ao divulgá-lo (ABRÃO, 2012).

O brinquedo é um objeto que não tem função precisa, ou seja, a criança o manipula 
livremente sem estarem condicionadas as regras ou a qualquer outro princípio de manipulação, de acordo com Brougère (1995, p.13), "Com certeza podemos dizer que a função do brinquedo é a brincadeira." Ao se estabelecer uma brincadeira não se deve limitar o agir da criança, pois o que ela faz tem sentido, seja ele qual for. Ao contrário do que muita gente pensa, a criança ao brincar se transfere para o mundo "do faz de conta", no qual objeto desempenha o papel de despertar imagens permitindo a criança dar sentido aos atos por ela praticados através da brincadeira.

É preciso entender que o brinquedo possui seu valor expressivo, pois estimula a imaginação, ao abrir uma variedade de situações decorrentes da manipulação da criança através da brincadeira, segundo Brougère (1995, p. 14):

\footnotetext{
A brincadeira não pode estar limitada ao agir: o que a criança faz tem sentido, é a lógica do fazer de conta e de tudo o que Piaget chama de brincadeira simbólica (ou semiótica). $\bigcirc$ objeto tem o papel de despertar imagens que permitirão dar sentido a essas ações.
}

Por meio das propagandas na televisão, a publicidade encontra sua chance de atrair a atenção das crianças, ao apresentar-lhes filmes e desenhos animados que mais tarde darão origem aos personagens dos brinquedos por elas utilizados. É de se esperar, num público tão "faminto" por novidades, que as indústrias multinacionais encontrem de fato uma forma de adequar o conteúdo simbólico dos brinquedos o mais perto possível da realidade desejada pelas crianças. Tudo isso serve para garantir a lucratividade da indústria de brinquedos, baseando-se especialmente na pressão estabelecida pela televisão que hoje encontra uma alternativa sutil de se dirigir ao público infantil (ABRÃO, 2013a).

Por muitas vezes o brinquedo deixou de representar sua função principal de instigar a ludicidade da criança, para corresponder a lógica da brincadeira e da expectativa daquele que a orienta (ABRÃO, 2013a). Cabe ressaltar a existência de brinquedos cuja compra tenha sido orientada pelos pais (para as crianças menores) e daqueles pedidos pela própria criança. No primeiro existe o valor representando a imagem para o adulto e a relação com a infância, reforçado pelas indústrias que se preocupam em fabricar brinquedos específicos para cada faixa etária das crianças. No segundo, o brinquedo pretendido identifica a criança com o mundo imaginário da qual ela incorpora sua personalidade a do brinquedo. Ao presentear um brinquedo à criança, os pais acabam transmitindo suas recordações de infância, que marcaram uma fase feliz de suas vidas, e as desejam aos seus filhos, ou por acreditarem serem educativos e adequados aos seus filhos.

Cada vez mais surge um novo brinquedo para ficar no lugar daquele que ficou ultrapassado, as indústrias se esforçam para transformar o objeto brinquedo em seres animados, cuja função principal é atrair o consumidor seja ele quem for - criança ou adulto. A publicidade do brinquedo é 
uma questão delicada, uma vez que seu público-alvo é o infantil. As crianças não têm discernimento nem autonomia nas relações de consumo, o marketing utiliza técnicas, as quais despertam o interesse das mesmas pelos produtos expostos na mídia, deixando de lado, muitas vezes, o brinquedo antigo e interessando-se pelo que está em evidência na televisão. "As pressões da propaganda na televisão, a publicidade, assim como os desenhos animados que dão origem aos personagens de brinquedos, levam a aumentar, ainda mais, a dimensão expressiva e simbólica do brinquedo, pela qual ele vai se diferenciar de todos os outros" (Brougère,1995, p.18). Isso mostra que, a preocupação da mídia e das empresas fabricantes do mesmo apenas visam o lucro, não tem interesse no aprendizado e no crescimento de quem o usa, ou seja, prevalece o capitalismo.

\section{O papel do brinquedo na cultura da criança}

A infância, no que se pode dizer, é uma apropriação de imagens e representações em diversos níveis de cultura, além de, também, ser uma categoria negociada em diferentes períodos históricos por adultos e crianças. A criança estabelece uma associação cultural entre a realidade que a cerca e o seu mundo, transpõe essa realidade para um universo imaginário no qual ela se sinta bem (ABRÃO, 2013b). Para exemplificar citamos a entrevista realizada com um menino sobre seu brinquedo favorito:

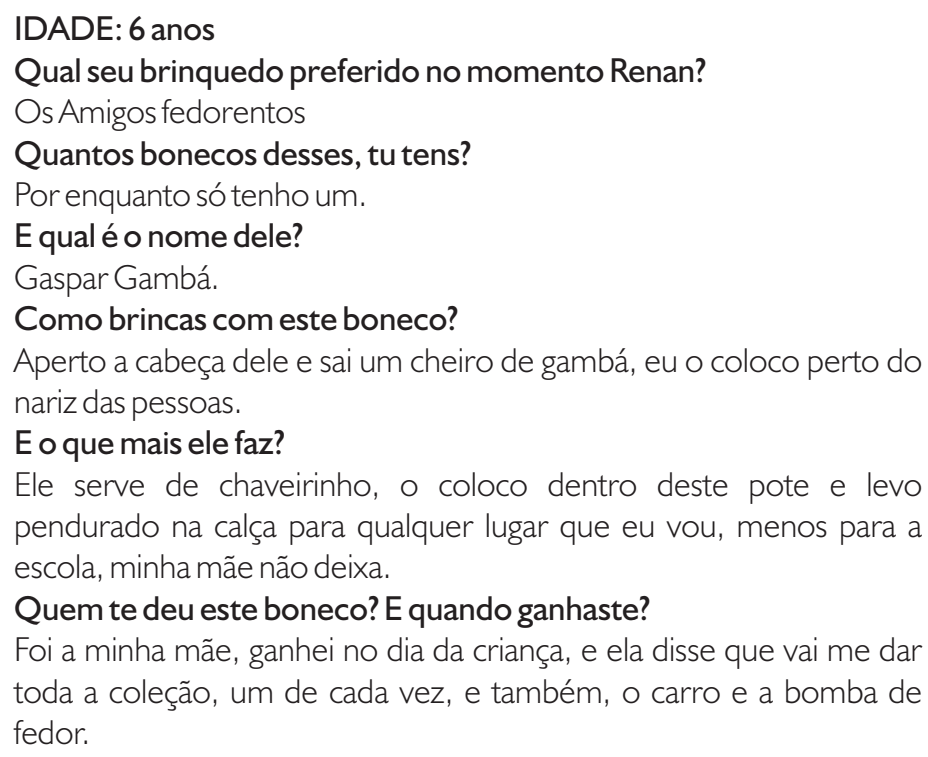

O menino falou um pouco sobre a história de Gaspar Gambá, pois cada boneco da coleção Amigos Fedorentos tem uma lenda em sua vida que lhes deram estes odores horríveis. Conta a lenda, que Gaspar Gambá e sua família foram a um depósito de lixo tóxico em uma floresta, de repente, Gaspar ouviu um barulho entre as árvores e foi ver o que era. Foi, então, que surgiu um gambá 
"super-poderoso" (palavras do menino) e jogou em sua direção um jato de xixi fedorento e contaminou Gaspar, este se sentiu poderoso por conseguir exalar o mau-cheiro de gambá pela boca cada vez que fala.

Cada cultura estabelece uma variedade de imagens consideradas bem expressivas no espaço cultural da criança. O brinquedo é o canal pelo qual a criança se desvencilha do real para vivenciar o "faz de conta" da brincadeira, ou seja, através da utilização do brinquedo, na brincadeira a criança vive a realidade imaginária do seu cotidiano sem sofrer as consequências provocadas por ele.

A representação elaborada pela criança permite estabelecer o aspecto funcional de cada brincadeira por ela elaborada. Assim, as brincadeiras são associadas em função das representações simbólicas que as crianças fazem do meio vivenciado. Toma-se, também, como exemplo, uma criança ao brincar com seu ursinho de pelúcia, que o manipula sem se preocupar com a representação cultural que corresponde a natural do urso, ou seja, este representa no universo infantil, um suporte de afetividade, pois é comum vermos esse tipo de brinquedo se tornar o companheiro inseparável de muitas crianças, chega até a se tornar seu protetor na hora de dormir (ABRÃO, 2013a).

A criança ao se afeiçoar ao brinquedo, estabelece um complexo significado cultural transmitido de geração a geração. O brinquedo simboliza tanto aos olhos das crianças quanto dos adultos a representatividade do original que se pretende. Ao se presentear uma criança com uma bonequinha bebê, fica bem explicito a introdução feita na brincadeira para criança, relacionando a boneca a um bebê e ao ato da maternidade (ABRÃO, 2013b).

No universo da brincadeira, estabelecido pelas crianças, a ludicidade reforça o simbolismo representado pelo brinquedo em relação a outros aspectos culturais. A Barbie é um exemplo de brinquedo que transmite a ideia adulta do mundo e sua influência perpassou as fronteiras de vários países. Esse brinquedo representa através de seus utensílios o universo da beleza, da riqueza e do luxo, pois estimula a compra de roupas pelas crianças que se imaginam fazendo parte dessa realidade, principalmente nas meninas, despertando a vaidade e transposição de seus desejos pelas características físicas da boneca, ou seja, a boneca é uma mulher, figura que as meninas imitam e desejam ser frequentemente. A boneca Barbie proporciona às meninas se projetarem numa realidade que elas desejam para si, através da brincadeira as meninas imaginam-se como a boneca e realizam seus sonhos futuros. "Assim, o mundo da Barbie ou da Xuxa são duas maneiras de representar as aspirações de uma menininha e de materializar seus desejos. Que uma venha dos Estados Unidos e a outra do Brasil não nos surpreendem" (BROUGÈRE, 1995, p. 37). Assim, o autor refere-se que ao virem desses dois países, ambas refletem padrões de beleza de corpos esculturais, cabelos loiros, olhos claros, entre outros atributos, que as crianças desde pequena já almejam alcançar, e as que assim não podem sentem-se frustradas e excluídas. 
A difusão da aceitação da boneca Barbie nos mais variados mercados expandiu-se de tal forma a passar do seu modelo inicial de princesa a inúmeras outras personagens utilizando-se do mesmo molde, alterando-se apenas o perfil para se assemelhar aos mais variados gostos das meninas. Sendo assim, o mercado conseguiu por meio de um único brinquedo estimular nas crianças uma imaginação pertinente ao universo por elas desejado. A Barbie foi criada por Ruth Handler e o seu marido Elliot em 1959, que tinham uma filha de nome Barbara. Observavam Barbara que brincava apenas com bonecas bebês quando criança. A garota era apaixonada por bonecas. Quando cresceu, já pré-adolescente, seu pai observou que Barbara ainda brincava com as suas bonecas. Então, a sua mãe, Ruth Handler, teve a ideia de criar uma boneca adolescente. O modelo original da Barbie foi baseado numa boneca erótica alemã. O primeiro lote de bonecas Barbie era tão parecido com a boneca original, que a Mattel teve de pagar uma indenização. A boneca foi vendida a 3 dólares, nos primeiros exemplares, que teve 340.000 bonecas. Logo após o seu sucesso de vendas foram criadas outros modelos de Barbies e logo a boneca também ganhou uma família: em 1961 chega seu namorado Ken.

A influência da Barbie nos dias de hoje é visível e sem dúvida marcante. Sempre existem comparações e citações da boneca mais vendida do mundo o tempo todo, costuma-se chamar alguém de Barbie por estar vestida de rosa, ou por ser loira. Isso prova que a Barbie valorizou uma linha de preocupação com a estética, beleza e ajudou a criar um padrão de beleza. A moda da boneca influencia a sociedade, pois ela sempre procura simbolizar uma garota bonita, inteligente, amiga, companheira, meiga e politicamente correta. A Barbie marcou gerações inteiras e continua até hoje, devido a personalidade que lhe foi associada e o padrão de beleza que simboliza. Não é raro muitas meninas e adolescentes quererem se parecer com a Barbie. A Barbie influenciou uma nova conduta em mulheres e crianças e criou uma nova identidade social que é perceptível em crianças, adolescentes e mulheres do mundo todo, mesmo sendo uma boneca originalmente estadunidense.

Ao entrevistarmos uma outra criança, uma menina, tivemos a oportunidade de avaliar e comparar as pesquisas sobre a influência da boneca Barbie no cotidiano das meninas: O brinquedo preferido pela menina foi a Barbie, quando perguntada como ela adquiriu o brinquedo, foi respondido que no dia do seu aniversário ela pediu a seu pai de presente, pois uma coleguinha dela tinha e ela adorava ver como a amiga brincava. Além de demonstrar como ela brincava com a casa da Barbie, ela revelou que todas as suas colegas reuniam-se algumas vezes para brincarem uma com a boneca da outra e assim todas poderiam vivenciar situações que cada Barbie poderia proporcionar. Ao ser questionada sobre as vantagens e desvantagens da boneca, ela respondeu que como vantagem pode inventar várias brincadeiras usando sua boneca e desvantagens que as vezes falta o cenário e os objetos para a brincadeira se tornar melhor. "Desse modo a boneca reflete para nós, depois de muitas mediações e transformações, nossas próprias representações, diretas ou indiretas, da infância" 
(BROUGÈRE, 1995, p.38). A criança projeta no brinquedo muitas de suas aspirações para o futuro.

Neste sentido, verificamos que existem alguns aspectos importantes, que além de despertar nas crianças os benefícios e alegrias que as atividades lúdicas, proporcionam, ao mesmo tempo, desenvolvem habilidades, atitudes, capacidades motoras, cognitivas, e também permite à elas fazerem descobertas de maneira que possibilitem a construir à sua identidade e autonomia por meio dessas brincadeiras, assim como os cinco sentidos que ajudam as crianças a perceberem, através do corpo tudo que acontece ao seu redor e que é essencial realizar as tarefas, por isso, é fundamental a criança aguçar esses sentidos.

\section{A construção da identidade através das brincadeiras}

Desde quando o indivíduo nasce ele começa a ser inserido no processo de socialização, isso ocorre através das próprias famílias com seus costumes, hábitos, condições socioeconômicas, assim, essa inserção no meio social acontece gradativamente e conforme a idade das crianças. Um dos fatores importantes nesse processo é a aquisição da linguagem, é quando a criança começa a dominar seu ambiente, compreender o significado das coisas que a rodeiam, imitar a fala dos adultos, responder para eles.

Nesse momento iniciam-se as novas descobertas, as crianças já são capazes de formular alguns conceitos sobre as pessoas e os objetos, bem como, estão construindo suas identidades a partir do olhar do outro, quando a criança em suas brincadeiras imita os adultos, pode-se dizer que ela está aprendendo a seguir um padrão de conduta que futuramente lhe ajudará a desempenhar um papel significativo na sociedade, imitar as pessoas do seu meio de convívio é a primeira noção de brincadeira que ela desenvolve, logo em seguida, a criança começa a inserir-se a outros ambientes e novas brincadeiras vão surgindo ampliando sua cultura lúdica, de acordo com Brougère (1995, p. 51): "Essa cultura lúdica não está fechada em torno de si mesma; ela integra elementos externos que influenciam a brincadeira: atitudes e capacidades, cultura e meio social. Os brinquedos se inserem nesse contexto." Ao brincar ela imita todos os aspectos familiares e sociais que ela vivencia em seu cotidiano.

Isso pode ser observado num simples brincar de uma menina com a boneca, ou do menino com o carrinho. Eles usam apenas um objeto brinquedo, mas, criam situações, objetos, personagens imaginários, de acordo com o meio social que vive. Um exemplo disso são as diferentes imaginações e atitudes de crianças que brincam com brinquedos iguais, mas, que moram na zona rural e urbana. Cada criança irá imaginar situações diferentes, as da cidade, podem mencionar grande fluxo de trânsito, violência, já as do campo, tratores, plantações, animais. Assim, ficam notáveis as influências 
e vivências da realidade de todas as crianças em suas próprias brincadeiras.

Observa-se, na contemporaneidade, a influência da TV no universo lúdico da infância, ela interfere diretamente nas brincadeiras tanto dos meninos, como das meninas através de filmes, desenhos animados, programas infantis, comerciais e inclusive telenovelas, as crianças, a partir do que assistem se transportam para aquele mundo fictício e reproduzem suas brincadeiras. Assumem papeis dos heróis, mocinhos, bandidos, das protagonistas dos programas e etc, isso dependerá da imagem que a personagem representará em seu mundo imaginário.

A sociedade é composta por várias culturas infantis, as quais variam desde as classes mais pobres até as mais abastadas, todavia, as brincadeiras acontecem em qualquer meio social, porém, de maneira diferenciada, cada criança desenvolve suas brincadeiras de acordo com a cultura a qual pertence, com as personagens e elementos que cercam o seu mundo, segundo Dornelles (2005, p. 90):

\begin{abstract}
A pertença de cada criança em diferentes grupos, ou num grupo específico, induz suas ações e seus comportamentos, inclusive de consumo. Isto faz com que a criança se identifique com os grupos nos quais é incluída, por uma política de inclusão. Tal política de inclusão produz os excluídos.
\end{abstract}

A diferenciação de classes existentes na sociedade, devido a um sistema econômico capitalista, remete ao problema da exclusão das crianças menos favorecidas, que na maioria das vezes, não conseguem acompanhar o mercado do consumo infantil, chegando, assim, a outro problema mais sério, o preconceito, pois, infelizmente a sociedade tem como objetivo construir modelos de pessoas padronizadas conforme a mídia. Ela identifica os indivíduos a partir do que eles possam ter e não pelo que são; gerando a seletividade social, o que de certa forma, acaba prejudicando as partes desfavorecidas. "A mídia produz assim sujeitos consumidores, essa subjetivação é produzida por um processo de individuação onde cada um é um sujeito identificado pelo uso de determinados produtos" (DORNELLES, 2005, p.91 apud DELUZE, 1992). Ou seja, isso exclui as crianças que não podem ser consumidoras, ou que compram produtos mais inferiores, fato que ocorre dentro do próprio contexto infantil.

A criança, independente do sexo, cor, raça, situação socioeconômica tem a necessidade de brincar, pois a brincadeira lhe proporcionará a possibilidade da inserção no meio social e, também, servirá como base para a construção de sua biografia, de sua identidade, segundo Brougère (1995, p.98), "A brincadeira pressupõe uma aprendizagem social", e ainda: "não é um comportamento específico, mas uma situação na qual esse comportamento toma uma significação específica" (BROUGÈRE, 1995, p.100). As meninas, por exemplo, ao brincarem com suas bonecas, estão construindo sua identidade de mãe, mulher, profissional, confirmando as palavras do autor, 
trouxemos o relato de outra criança: A menina relata que seu brinquedo preferido é uma boneca StephanyBeauty, que ela denomina Nicole. Ao ser questionada, o porquê da escolha do nome de boneca, diz ser por achar bonito.

Então, explica as características da boneca: ao apertar na barriga da boneca ela fala (vamos brincar? vamos limpar minha orelhinha? vamos começar de novo? passa batom rosinha na minha boca? você gosta de se arrumar? eu adoro! passa sombra nos meus olhos?).

A menina diz que a boneca foi uma escolha sua, ao ir a uma loja com sua avó pediu de presente e ganhou-a de natal. Quando questionada por que gosta dessa boneca, explica por ter maquiagem. Também a menina afirma que não trocaria o brinquedo por nenhum outro.

Portanto, o brincar tem um significado muito importante na infância, através dele, a criança expressa suas experiências, criatividade, curiosidades, além de ser um aspecto relevante na aprendizagem.

\section{Considerações}

Levando-se em consideração os aspectos socioculturais da criança com seu brinquedo ou outro produto de consumo, verifica-se que o processo educacional rege todas as etapas da formação do ser crítico. Para formação deste faz-se necessário um conjunto de atribuições repassadas através das instituições formais e informais. A primeira desta tem seu maior representante na família, a última é formada pela estimulação de opiniões que se formam nas crianças através das propagandas de produtos pela televisão.

Nesse contexto verifica-se que a brincadeira faz parte de um processo interrelacional entre a parceria criança - brinquedo e influências da sociedade como um todo. A partir daí forma-se a personalidade do indivíduo, caracterizando-o como um ser de vontade e interpretações próprias adquiridas através das propagandas de brinquedos e de outros produtos que lhes são disponibilizados.

A importância do brincar na vida de uma criança envolve diferentes tipos de jogos e brincadeiras, das solitárias as grupais, das simbólicas as de execução, colocando em evidência a contribuição que os brinquedos trazem ao processo de desenvolvimento infantil e a interação com o ambiente.

A influência externa do ambiente publicitário evidencia-se a partir das relações interdisciplinares verificadas nas crianças que tem a sua personalidade composta tanto pelo ambiente familiar, como pelo externo. Compete aos pais a tarefa de conscientizar seus filhos, quanto ao que é do seu gosto ou ao que foi introduzido por propagandas. Só assim conseguiremos conscientizar as 
crianças sobre os riscos eminentes do consumo desenfreado de produtos que às vezes nem elas precisam realmente.

Por outro lado, o brinquedo pode ser considerado condicionante ao estruturar representações imaginárias e comportamentos lúdicos, mas ele também permite uma interiorização personalizada, com invenções, e criações; então a brincadeira distancia-se das determinações contidas no objeto. Assim, permite que a criança possa reconstruir e re-significar o ato de brincar distanciando do que é imposto pela mídia.

As brincadeiras não devem ser vistas ou consideradas como um mero passatempo, pois além delas serem indispensáveis para o desenvolvimento da criança, elas promovem os processos de socialização e descobertas. Entre uma delas é quando a criança, ainda bebê, através das brincadeiras em que batem com as pernas no chão, se apoia nos móveis e vão descobrindo que podem ficar em pé, além das diferentes sensações de frio, de quente, a consistência dos alimentos estimulando o prazer. Por fim, preciso preservar a iniciativa da criança dando à ela, no ato de manipulação com o brinquedo, liberdade de escolha e ação através de seu uso. Assim, irá contribuir com a construção do sujeito infantil em uma perspectiva comprometida com o exercício da liberdade e poder. 
ABRÃO, Kelber. O espaço o movimento e o brincar no período de transição da Educação Infantil e o primeiro ano. 2011. Dissertação (Mestrado em Educação Física), Universidade Federal de Pelotas, Pelotas, 2011.

A política de organização das infâncias e o currículo da Educação Infantil e do primeiro ano. Zero-a-seis, v.1. Florianópolis: UFSC, 2012.

Quando a alegria supera a dor: jogos e brinquedos na recreação escolar. Atos e pesquisas na Educação, v.8. Blumenau: Furb, 2013a.

A corporeidade infantil nos espaços da escola. Vivências, v.16.Erechin: URI. 2013b.

BROUGÉRE, Gilles. Brinquedo e Cultura. São Paulo: editora Cortez, 1995.

DORNELLES, Leni Vieira. Infâncias que nos escapam: Da criança de rua à criança cyber. Petrópolis, RJ: editora Vozes, 2005.

SOUZA, Solange Jobim e (org.). Subjetividade em questão: a infância como crítica da cultura, capítulo: Infância, violência e Consumo. Rio de Janeiro: editora 7letras, 2000.

POSTMANN, Neil. O desaparecimento da infância. Rio de Janeiro: Graphia, 1999. 